\title{
Obituary
}

\section{The Influence of Morton Kramer in Research on Mental Health and Aging}

Professor Morton Kramer, age 84, died on August 17, 1998, in Pikesville, Maryland, USA, near Baltimore. He is survived by three children and their families. $\mathrm{He}$ is remembered by hundreds of students, friends, and colleagues around the globe.

As a young man, Mort was an enthusiastic scholar and student-athlete at Baltimore City College and Johns Hopkins University. While studying undergraduate chemistry, Mort met statistician Jacob Yerushalmy, who encouraged him to pursue doctoral studies with Professors Lowell Reed and Carroll Palmer in the Hopkins Department of Biostatistics. Graduating with a Doctor of Science degree in 1940, Mort first gained practical experience in various public health and census posts before he joined James Doull at Case Western Reserve University in a program of applied public health research on poliomyelitis and other infectious diseases. By 1946, Doull had recruited Mort to be Chief of Research and Information for the Office of International Health Relations, a newly formed unit of the National Institutes of Health (NIH). Through Doull and Reed, Mort could trace his biostatistical lineage back 150 years to the numerate clinician Pierre Charles Alexander Louis of France and, through Louis, to William Farr of Great Britain.

If Mort modeled his scientific work on predecessors, they were William Farr, widely recognized as founding father of "vital statistics," and Farr's contemporary in America, Edward Jarvis, best known for Jarvis's Law, a thesis that links home-to-hospital proximity with the probability of mental hospitalization. Farr took life table methods crafted by Edmund Halley of comet fame, and applied these methods to the study of birth and death records of his time. Mort took the same life table methods and used them to bring a more numerate approach to psychiatry. Farr was the 19th-century master of vital statistics in general. Kramer became the 20th-century master of vital statistics as applied to psychiatry and the first biostatistician to devote essentially all of his professional life to psychiatric statistics and epidemiology.

Like Jarvis before him, Mort was fascinated by the information to be extracted from routinely gathered mental hospital and census records. Mort's first contributions to research on mental health and aging involved careful life table analyses of mental hospital admissions, discharges, and deaths during the era prior to mass deinstitutionalization of patients 
with serious mental disorders. With his colleagues Ben Z. Locke and others, Mort was one of the first to recognize the impact of discharge and death rates on the composition of the mental hospital patient population. They demonstrated how this population was aging, highlighting the implications for patient flow and for patterns of care within these institutions.

Mort became the National Institute of Mental Health's (NIMH) first Biometrics Branch Chief in 1949. In this capacity, he was able to sustain international work that began when he was NIH advisor to the first World Health Assembly in 1948; his influence on psychiatric statistics soon became global. Via research on admissions to psychiatric care in the United States, England, and Wales, he built up a solid base of evidence on what others had suspected about a U.S. excess of schizophrenia diagnoses and a U.K. excess of manic-depressive illness diagnoses; this work subsequently was published in the journal Geriatrics. Mort recognized that this evidence would remain inherently unstable until there was greater uniformity in the concepts and methods of psychiatric assessment. He used his NIMH influence to support a line of comparative U.S.-U.K. research that sought the elusive goal of diagnostic comparability. Long-term results of this international collaboration have included development of the standardized Present State Examination and CATEGO, later refined for the World Health Organization's International Pilot Study of Schizophrenia. The Composite International Diagnostic Interview (CIDI) and the Schedule for Clinical Assessment in Neuropsychiatry (SCAN) are more recent elaborations along the same lines.

Mort's international work had a domestic complement. With his NIMH group, Mort organized a model reporting system for state-level information about mental hospital admissions, as well as a small collection of psychiatric case registries. As a result of this work, information on psychiatric care in the U.S. and in many other countries of the world is based upon standard conventions and definitions for sometimes elusive concepts such as "first admission" and "readmission," and there is greater standardization in diagnostic classifications. Mort also was able to enforce agreements about less challenging but still important issues such as how to achieve comparability when framing age categories and raceethnicity subgroups in statistical reports on admissions, discharges, and deaths.

Mort was careful to leave a trace of his work in his own journal articles and monographs or those authored by others. In the domain of aging research, his first contribution, published in 1940 , was a study of fluorine's effect on the life span of rachitic rats. An especially influential set of monographs and articles emerged from his investigations on patient flow through American psychiatric hospitals, published in the American Journal of Public Health and the American Journal of Mental Deficiency. The original U.S.-U.K. study on psychiatric diagnoses led to a new research initiative on corresponding issues for geriatric psychiatry, with collaborating psychiatrists now well known in geriatrics, including Barry Gurland, Anthony Mann, and J. R. Copeland, as well as new assessment tools they developed (e.g., Comprehensive Assessment and Referral Evaluation [CARE] and Automated Geriatric Examination for Computer Assisted Taxonomy [AGECAT]).

In the 1960s, Mort began advancing the germ of an idea that there should be 
a collaborating network of epidemiological field stations, each with responsibility to gather and report psychiatric statistics for a local "catchment area" population. In 1976, after a career of 30 years of civil service at the federal level, Mort returned to his alma mater and became Professor of Mental Hygiene and Biostatistics on the Johns Hopkins faculty. Subsequently, his idea evolved into the NIMH Epidemiologic Catchment Area (ECA) surveys. In the late 1970s, he became Principal Investigator for the Baltimore arm of the ECA surveys, and over the next 20 years, he framed and carried out several lines of research on mental disorders that grew from his prior work at NIMH. In particular, he sought to clarify the nature and frequency of mental disorders affecting Baltimore's elderly residents; the co-occurrence of psychiatric and other medical conditions; the impact of population-level demographic changes on the numbers of citizens affected by mental disorders; the importance of household composition in relation to mental health; and the suspected excess mortality associated with presence of psychiatric disorders.

It now seems that the most influential of Mort's late-life articles cover two related topics: "the rising pandemic of mental disorders and associated chronic disabling conditions" and "the barriers to effective prevention of mental disorders." In these papers, Mort added important numerical facts to bolster a growing awareness about demographic trends that have influenced the numbers of individuals with mental disorders. First appreciated more than 50 years ago, these facts have been used by some of the more developed nations of the world in plans for increasing numbers of cases of Alzheimer's disease and related dementias. Mort's work reminds us that the less developed nations are not spared in the intersection of demographic trends with age-specific prevalence values. As readers of this journal may well know, in these countries the effects of reduced infant mortality rates are first appearing in the form of increases in numbers of young and middle-aged adults who have alcohol dependence, drug dependence, and major depression, and later appearing in terms of increased numbers of patients with the dementias and other mental disorders that have peak onset in the seventh decade of human life and beyond.

Not long before his death, Mort shared some new ideas for analyses and articles on the excess mortality associated with mental disorders found in the first Baltimore ECA survey. Although Mort's journey has taken him "across the bar," we now count on Mohamed Badawi, William W. Eaton, and others among us who had the good fortune to be his students, friends, or colleagues. We will see to it that this work is carried out and published in his memory.

Mort's influence will last beyond the memory of scientific articles and monographs that bear his name and the names of his collaborators. He passed along a commitment to numeracy he had received from Pierre Charles Alexander Louis, through others, over a span of two centuries. More than his articles and monographs, this aspect of Mort's legacy will live into the 21 st century and, we hope, far into the future he tried so hard to project.

James C. Anthony, PhD Professor of Mental Hygiene Johns Hopkins University Baltimore, MD, USA 
Postscript: A memorial conference honoring the memory and contributions of Morton Kramer will be held in Baltimore on May 14, 1999, just before the annual meeting of the American Psychiatric Association in Washington, DC. Informa- tion about this conference may be obtained from members of the organizing committee, which includes: janthony@ jhu.edu, weaton@jhsph.edu, jbreitner@ jhsph.edu, \& skellam@welchlink.welch. jhu.edu

\section{\$ Springer Publishing Company}

\section{End of Life Issues}

\section{Interdisciplinary and Multidimensional Perspectives}

Brian de Vries, $\mathrm{PhD}$

This book examines the ways in which individuals at the end of life are influenced by aspects of their interpersonal and social environments. For gerontologists, psychologists, hospice workers, counselors, nurses, and physicians.

Partial Contents: Part I: Individual/Personal Issues - Age Cohort Differences in Perceptions of Funerals - Grief and the Self-Concept - Facilitating Perceived Control in The Dying Process • Part II: Interpersonal/Microsystem Issues • The Impact of Bereavement on Families • Grandparent Participation in Time of Family Bereavement - Part III: Social/Exosystem Issues - Effective Communication of the Long-Term Care Resident's Life-Prolonging Treatment Wishes - Physician Communication With Seriously Ill Cancer Patients - Part IV: Cultural and Institutional/Macrosystem Issues - The Changing Demography of Death in the US • Physician-Assisted Suicide 1999 304pp (est.) 0-8261-1260-9 hardcover $\$ 39.95$ tentative

536 Broadway, New York, NY 10012-3955 • (212) 431-4370 • Fax (212) 941-7842 